\title{
Effects of Screen Size on Biochemical Conversion of Big Bluestem Biomass for Biofuel Production
}

\author{
Xiaoxu Song, ${ }^{1}$ Meng Zhang, ${ }^{1}$ Ke Zhang, ${ }^{2}$ Z. J. Pei, ${ }^{1}$ and Donghai Wang ${ }^{2}$ \\ ${ }^{1}$ Department of Industrial and Manufacturing Systems Engineering, Kansas State University, Manhattan, KS 66506, USA \\ ${ }^{2}$ Department of Biological and Agricultural Engineering, Kansas State University, Manhattan, KS 66506, USA \\ Correspondence should be addressed to Meng Zhang; meng@ksu.edu
}

Received 29 January 2015; Revised 30 May 2015; Accepted 2 June 2015

Academic Editor: Jiang Jianchun

Copyright (c) 2015 Xiaoxu Song et al. This is an open access article distributed under the Creative Commons Attribution License, which permits unrestricted use, distribution, and reproduction in any medium, provided the original work is properly cited.

\begin{abstract}
Biomass size reduction is the first step for biofuel production from cellulosic biomass through biochemical pathway, and it is usually performed on a mill with screen installed to control the size of the produced particles. The absence of in-depth knowledge about the effects of screen size throughout the biochemical conversion of cellulosic biomass makes it difficult to choose the screen size to conduct biomass size reduction to minimize the energy consumption on mills, maximize the cellulose recovery rate after pretreatment, and maximize the enzymatic hydrolysis efficiency. The objective of this work is to address this issue by generating new knowledge on the effects of screen size in these three processes: size reduction, pretreatment, and enzymatic hydrolysis in conversion of big bluestem biomass for biofuel production. Four screen sizes used in this study were 1, 2, 4, and $8 \mathrm{~mm}$. It was found that using a larger screen size saved energy in biomass size reduction on a knife mill. Moreover, particles produced with larger screen sizes achieved higher cellulose recovery rate after pretreatment, higher enzymatic hydrolysis efficiency, and higher total sugar yield.
\end{abstract}

\section{Introduction}

There is a growing need to find alternatives to petroleumbased liquid transportation fuels $[1,2]$. Recognized as promising alternatives are biofuels produced from cellulosic biomass (including dedicated energy crops such as big bluestem, forest residues, and agricultural residues) [3-5]. Using cellulosic biomass as the feedstock for biofuel production is advantageous because of its low cost, abundance, and sustainability [6]. An investigation jointly supported by the U.S. Department of Energy and Department of Agriculture shows that land resources in the U.S. are sufficient to sustain production of enough cellulosic biomass (about 1 billion dry tons) annually to replace $30 \%$ or more of the nation's current consumption of liquid transportation fuels [3-5].

Conversion of dedicated energy crops such as big bluestem (Andropogon gerardii) to biofuels offers major economic and environmental benefits [7]. Big bluestem is a dominant grass in the tallgrass prairies of North America and comprises up to $80 \%$ of the prairie biomass in the midwest grassland in the United States $[8,9]$. Big bluestem biomass can be converted into ethanol biofuels through biochemical pathway. Figure 1 illustrates the major steps in the conversion. First, big bluestem biomass size reduction is necessary because current conversion technologies cannot efficiently convert whole stems of big bluestem biomass into ethanol biofuels $[10,11]$. The biomass size reduction is usually conducted on a knife mill [12] or hammer mill [13-16] to produce particles with sizes from 0.1 to $10 \mathrm{~mm}$ [17]. In knife milling (Figure 2), biomass comes into contact with cutting knives equipped on a rotor in the chamber. Biomass is cut between the knives and the cutting bars. Particles that are smaller than the screen size will pass through the openings on the screen; those larger than the screen size will be recirculated and continue being milled. In hammer milling (Figure 3), hammers are mounted on a rotating drum. Size reduction is performed through impact-induced material fragmentation. Second, pretreatment can make cellulose biomass more accessible to enzymatic hydrolysis through various mechanistic effects including enzyme accessible surface area increases, cellulose decrystallization, hemicellulose removal, lignin removal, and lignin structure alteration [18]. Hydrolysis breaks polysaccharide into component sugars that are convertible to ethanol by fermentation [6]. Finally, the 


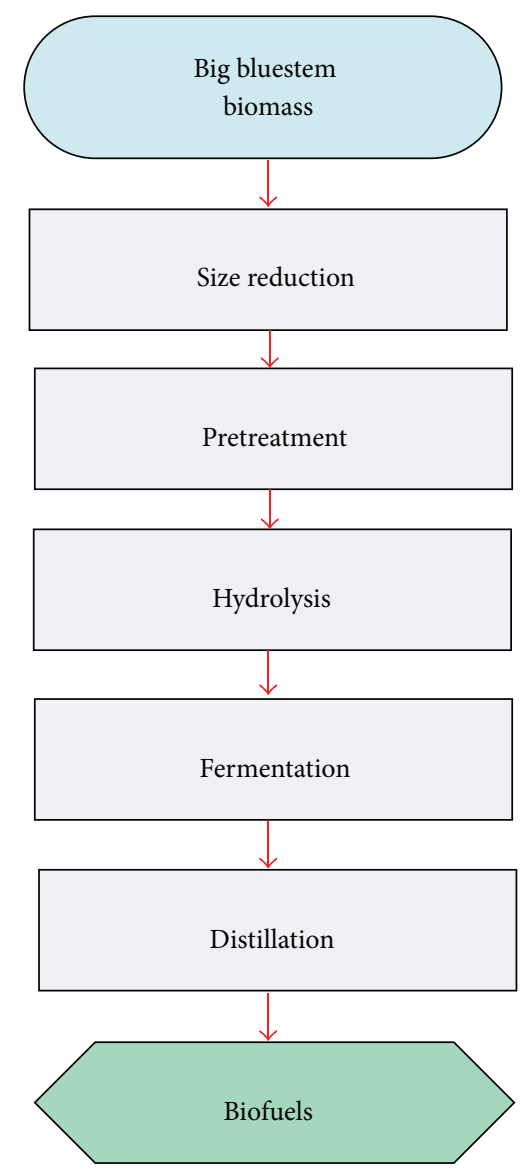

FIGURE 1: Major steps in biochemical conversion of big bluestem biomass into biofuels.

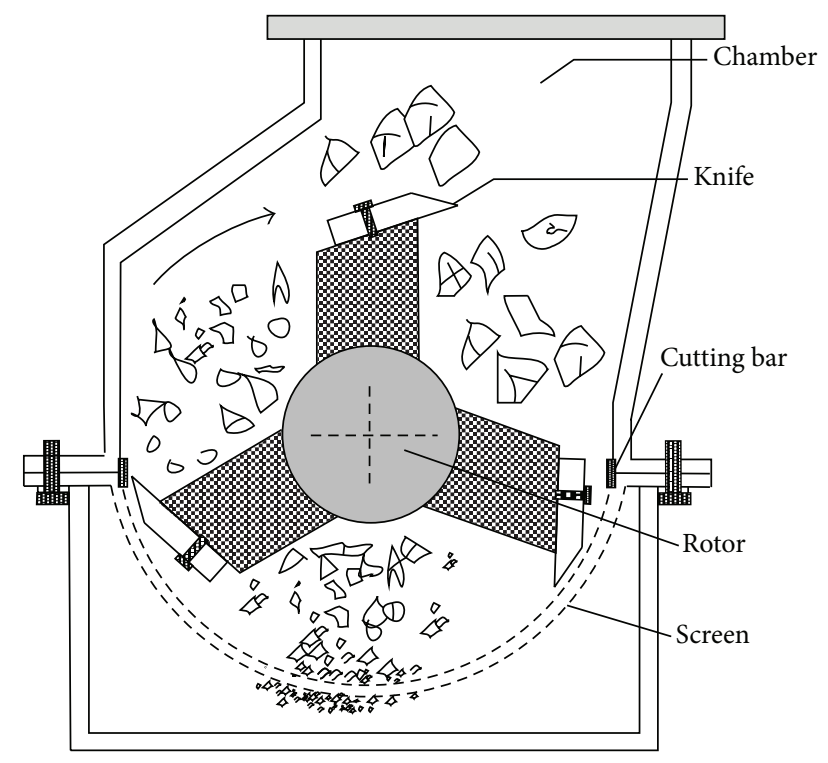

FIGURE 2: Illustration of a knife mill.

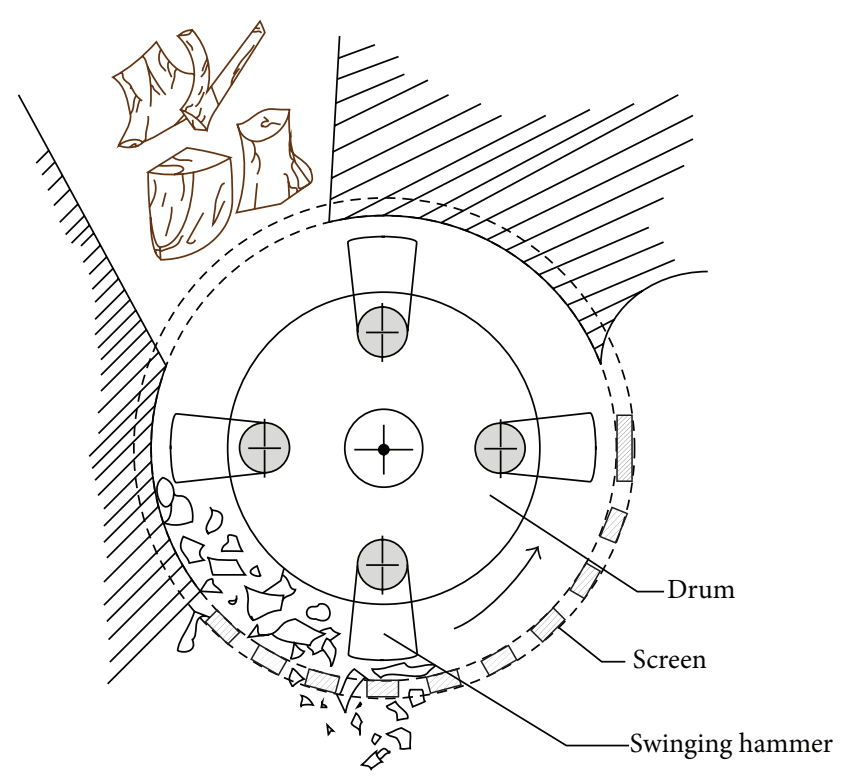

FIGURE 3: Illustration of a hammer mill.

fermented liquid is moved into a distillation system where the liquid is heated to take advantage of the different boiling points of ethanol and water. The difference will enable the extraction of about $95 \%$ pure fuel-grade ethanol [6]. It is also known that fermentable sugar yield in hydrolysis is approximately propositional to the biofuel yield in fermentation [19].

The effect of screen size on energy consumption in biomass size reduction has been studied in the literature. It has been consistently observed that energy consumption in biomass size reduction increased greatly when smaller screen sizes were installed [20-22]. Nevertheless, these studies either were not for biofuel production purpose or did not include the biochemical conversion of produced particles to fermentable sugar. Many other reported studies included biomass biochemical conversion to ethanol biofuels with biomass particles produced by size reduction but did not cover energy consumption in biomass size reduction [23-25].

The absence of in-depth knowledge about the effects of screen size throughout the biochemical conversion of cellulosic biomass makes it difficult to choose the screen size to conduct biomass size reduction in order to minimize the energy consumption on mills, maximize the cellulose recovery rate after pretreatment, and maximize the enzymatic hydrolysis efficiency. The objective of this work is to address this issue by generating new knowledge on effects of screen size in these three processes: size reduction, pretreatment, and enzymatic hydrolysis, using big bluestem biomass.

\section{Material and Methods}

2.1. Material. The material used in this study was big bluestem harvested from the United States Department of Agriculture Plant Material Center (Manhattan, KS, USA). The entire plant except the root was used. The moisture content of the big bluestem was 5\%. Biomass moisture content 


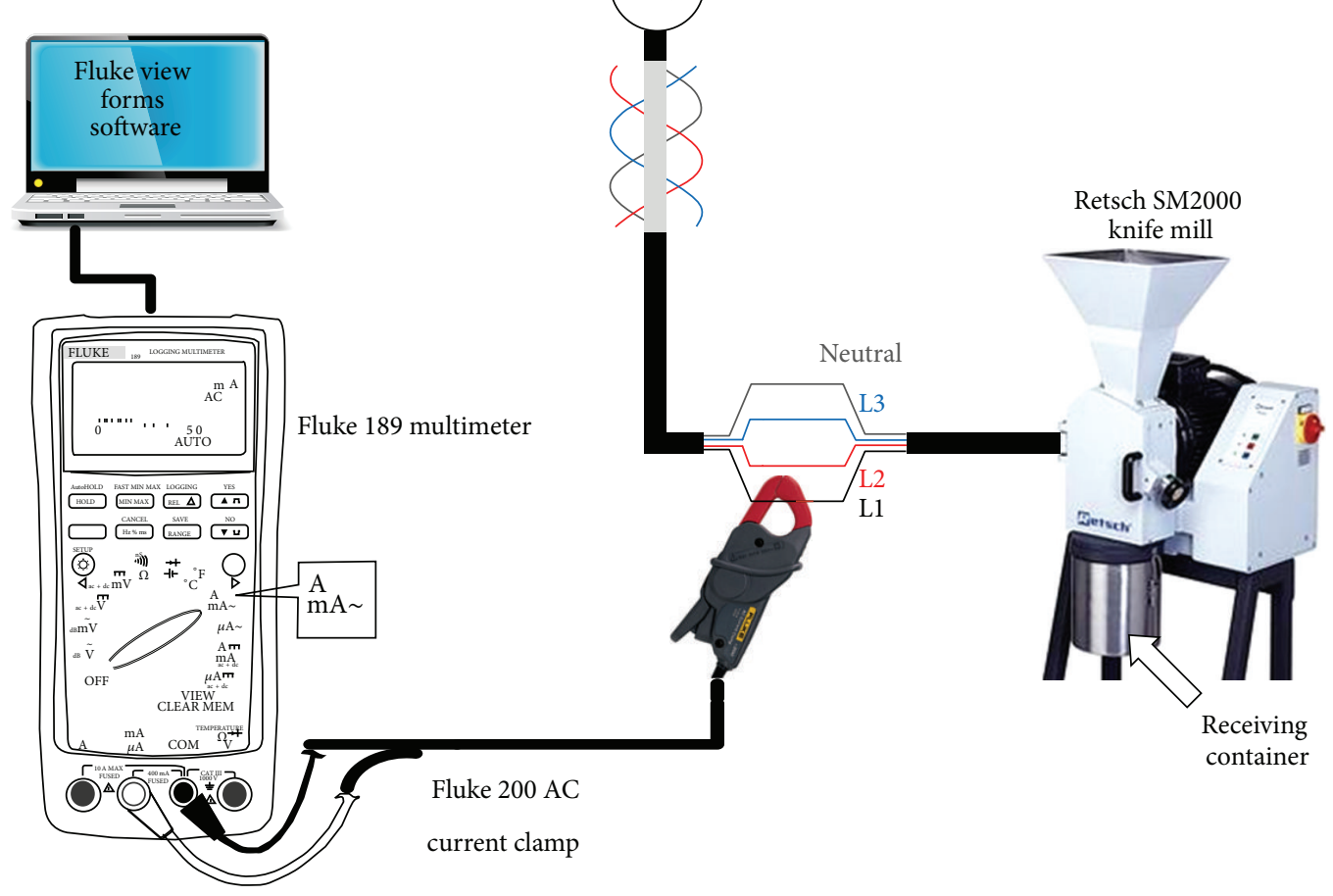

FIGURE 4: Experimental setup.

TABLE 1: Chemical compositions (\% dry weight basis) of big bluestem.

\begin{tabular}{lc}
\hline Component & Percentage \\
\hline Cellulose & $35.9(0.4)$ \\
Hemicellulose & $25.4(0.5)$ \\
Lignin & $24.0(0.7)$ \\
\hline
\end{tabular}

was determined by following the laboratory analytical procedures developed by the National Renewable Energy Laboratory [28]. Chemical compositions of cellulose, hemicellulose, and lignin are listed in Table 1 [29].

2.2. Biomass Size Reduction. The experimental setup for size reduction is shown in Figure 4. A knife mill (SM 2000, Retsch $\mathrm{GmbH}$, Haan, Germany) was used. It was powered by a $1.5 \mathrm{~kW}$ electric motor. The milling chamber of the mill is pictured in Figure 5. The knife mill is equipped with three knives $(95 \times 35 \mathrm{~mm})$ on the rotor and four cutting bars mounted on the inside wall of the milling chamber. Big bluestem biomass was cut and sheared into particles between the knives and the cutting bars. A screen $(145 \times 98 \mathrm{~mm})$ was installed at the bottom of the milling chamber. Four screen sizes $(1,2,4$, and $8 \mathrm{~mm})$ were used in this study. Figure 6 shows a $4 \mathrm{~mm}$ screen as an example.

Before starting one size reduction test, the knife mill was run for 10 seconds without loading any biomass to avoid current spikes. Figure 7 shows a typical current chart when the knife mill was running empty. There was a current spike

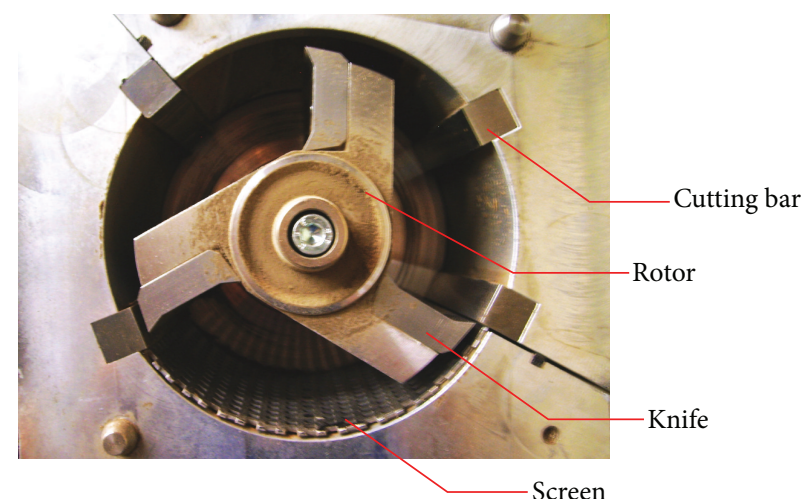

FIGURE 5: Milling chamber of the knife mill.

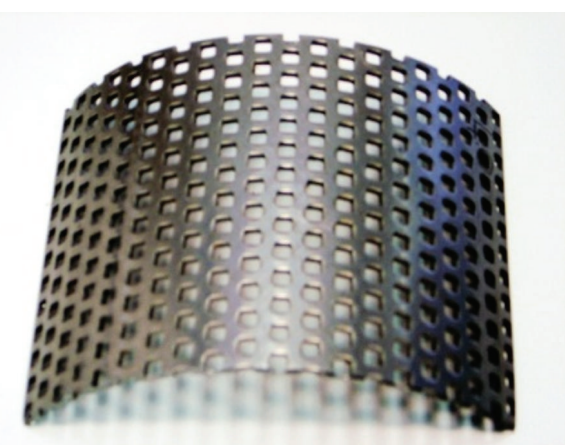

Figure 6: Screen used on the knife mill (screen size $=4 \mathrm{~mm}$ ). 


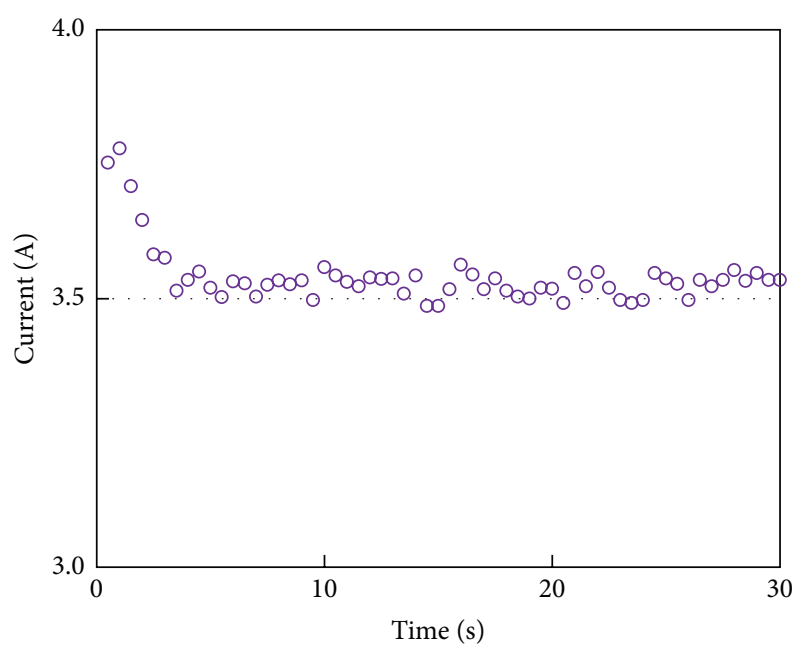

FIgURE 7: A typical current chart for 30 seconds after the knife mill starts without load.

in the first few seconds after the knife mill was turned on. After 10 seconds, the current stayed stable and ten stems of big bluestem were loaded into the milling chamber (one stem is about $50 \mathrm{~cm}$ long and $0.5-1 \mathrm{~cm}$ wide). During the milling process, more big bluestem stems were loaded into the milling chamber manually by a mill operator at a rate that could keep the milling chamber full. For one size reduction test, the total amount of big bluestem loaded was 400 grams. The mill was turned off after 10 seconds when all the 400 grams of biomass was loaded into the milling chamber. After each test, the weight of the big bluestem particles collected from the receiving container was measured. Not all the 400 grams of biomass could be collected from the receiving container, because there was still biomass retained in the milling chamber when the mill was turned off. Between of two consecutive size reduction tests, the milling chamber was opened to remove any biomass left there, and the chamber was cleaned with compressed air.

2.3. Sugar Conversion. In this study, big bluestem sugar conversion consisted of dilute sulfuric acid pretreatment and enzymatic hydrolysis. In dilute sulfuric acid pretreatment, 10 grams (dry weight) of big bluestem particles produced with each screen size and $200 \mathrm{~mL}$ of $2 \%(\mathrm{w} / \mathrm{v})$ sulfuric acid were loaded in a $600 \mathrm{~mL}$ glass liner of a Parr pressure reactor (4760A, Parr Instrument Co., Moline, IL, USA). Pretreatment time was $30 \mathrm{~min}$, and pretreatment temperature was $140^{\circ} \mathrm{C}$. This pretreatment condition was selected based on a previous study conducted by the authors using the same type of biomass [30].

After pretreatment, big bluestem particles were washed with $50-60^{\circ} \mathrm{C}$ distilled water using a suction filtration system with P4 grade filter paper (Fisher Scientific Inc., Waltham, MA, USA) to conduct solid-liquid separation. The solid biomass after filtration was carefully collected from the filter paper using a stainless steel micro spatula. The dry weight of the collected solid biomass was measured; then a small portion of the solid biomass was used for biomass composition analysis, and the rest was used for subsequent enzymatic hydrolysis. The liquid after filtration was removed, which included dissolved sugars, acid residues, and inhibitors (substances that could decrease enzymes' ability to break cellulose into glucose) formed during pretreatment.

Enzymatic hydrolysis was carried out in eight $125 \mathrm{~mL}$ flasks in a water bath shaker (C76, New Brunswick Scientific, Edison, NJ, USA) at $50^{\circ} \mathrm{C}$ for $48 \mathrm{~h}$. The agitation speed of the water bath shaker was $110 \mathrm{rpm}$. There were two flasks containing big bluestem particles produced with each of the four screen sizes. Each flask contained $50 \mathrm{~mL}$ of hydrolysis slurry. The slurry consisted of $4 \%(\mathrm{w} / \mathrm{v})$ biomass on dry weight base, sodium acetate buffer $(50 \mathrm{mM}, \mathrm{pH}=4.8)$, and $0.02 \%(\mathrm{w} / \mathrm{v})$ sodium azide to prevent microbial growth during hydrolysis. Accellerase 1500 enzyme complex (Danisco USA, Inc., Rochester, NY, USA) was used. The enzyme loaded was $0.5 \mathrm{~mL}$ for each gram of dry biomass.

\section{Measurement and Calculation}

3.1. Energy Consumption in Biomass Size Reduction. Energy consumption in biomass size reduction was measured as the electricity consumed by the electric motor of the knife mill. As illustrated in Figure 4, electric current to the motor was measured using a Fluke 200 AC current clamp connected to a Fluke 189 multimeter (Fluke Corp., Everett, WA, USA). The 3-phase AC power supply in this study was in a $\mathrm{Y}$ configuration with four wires (3 phases: L1, L2, L3, and neutral). Electric current readings were collected by software (FlukeView Forms Basic, Fluke Corp., Everett, WA, USA) with a sampling rate of two readings per second. Data acquisition began after the initial ten stems of big bluestem were loaded into the milling chamber and stopped until the mill was turned off.

The data acquisition software recorded the average current $\left(I_{\mathrm{AVE}}\right)$. The voltage $(V)$ was $208 \mathrm{~V}$. The energy consumed in one size reduction test ( $t$ seconds) $(P)$ was calculated as follows:

$$
P=\frac{\sqrt{3} \cdot I_{\mathrm{AVE}} \cdot V \cdot t}{3600}(\mathrm{Wh})
$$

Dividing $P$ by the weight $(w)$ of the big bluestem particles collected after the test would give energy consumption $(E)$ per unit weight as follows:

$$
E=\frac{P}{w}(\mathrm{Wh} / \mathrm{g})
$$

3.2. Biomass Composition. Carbohydrates (cellulose and hemicellulose) and lignin make up a major portion of cellulosic biomass. Cellulose can be converted to fermentable sugar (glucose) in enzymatic hydrolysis. Hemicellulose is also sugar component; however, almost all of the hemicellulose will be decomposed by dilute sulfuric acid pretreatment. Lignin contains no sugar [31]. Biomass composition analysis is needed for the analyses in Section 4. After measuring the dry weight of biomass before and after pretreatment $\left(W_{\mathrm{BP}}\right.$ 
and $\left.W_{\mathrm{AP}}\right)$, biomass weight loss in pretreatment $(L)(\%)$ was calculated as follows:

$$
L(\%)=\frac{W_{\mathrm{BP}}-W_{\mathrm{AP}}}{W_{\mathrm{BP}}} \times 100 \% .
$$

In this study, biomass composition after pretreatment was determined according to the laboratory analytical procedures developed by the National Renewable Energy Laboratory [32]. Briefly, after pretreatment, biomass collected for composition analysis was dried in an oven (Isotemp 500 Series, Fisher Scientific Inc., Waltham, MA, USA) at $40^{\circ} \mathrm{C}$ for $48 \mathrm{~h}$. About $0.3 \mathrm{~g}$ of oven-dried biomass sample was soaked in $72 \%$ sulfuric acid at $30^{\circ} \mathrm{C}$ for $1 \mathrm{~h}$ with constant stirring. Then, it was diluted to a $4 \%$ acid solution and heated at $120^{\circ} \mathrm{C}$ for another $1 \mathrm{~h}$. After heating, the liquid and solid parts of the biomass sample were separated by suction filtration. The liquid part was adjusted to $\mathrm{pH}$ neutral by adding calcium carbonate; then the cellulose and hemicellulose contents in the liquid part were measured by a high-performance liquid chromatography (HPLC) system (Shimadzu, Kyoto, Japan), and the acid-soluble lignin content in the liquid was detected by a UV-visible spectrophotometer (BioMate 3, Thermo Electron Corp., Madison, WI, USA). The solid part was placed in a furnace at $575^{\circ} \mathrm{C}$ for $24 \mathrm{~h}$. The weight difference between the dry solid and ash residue after furnace heating was reported to be acid-insoluble lignin. The sum of the acid-soluble and acid-insoluble lignin contents was the total lignin content. Two duplications for each biomass sample were measured. Biomass composition reported in this study was the weight percentage of cellulose, hemicellulose, and lignin.

3.3. Sugar Analysis. After $48 \mathrm{~h}$ of enzymatic hydrolysis, sugar contents in the biomass samples were determined by analyzing the supernatant from the hydrolysis slurry using an HPLC system (Shimadzu, Kyoto, Japan). HPLC is an analytical tool for separating and quantifying components in complex liquid mixtures. The HPLC system was equipped with an RCM-monosaccharide column $(300 \times 7.8 \mathrm{~mm}$; Phenomenex, Torrence, CA, USA) and a refractive index detector (RID10A, Shimadzu, Kyoto, Japan). The column was eluted with double distilled water at a flow rate of $0.6 \mathrm{~mL} / \mathrm{minute}$, and the temperature of the column was maintained at $80^{\circ} \mathrm{C}$.

Cellulose recovery rate after pretreatment $\left(R_{P}\right)$ is used to evaluate how much cellulose can be recovered in the pretreatment. It is calculated as the ratio of the cellulose weight after pretreatment to the cellulose weight before pretreatment:

$$
R_{P}(\%)=\frac{C_{\mathrm{AP}}}{C_{\mathrm{BP}}} \times(1-L),
$$

where $C_{\mathrm{AP}}(\%)$ is the cellulose content in the biomass after pretreatment, $C_{\mathrm{BP}}(\%)$ is the cellulose content in the biomass before pretreatment, and $L(\%)$ is the biomass weight loss in pretreatment. These two cellulose contents were obtained by biomass composition analysis. Higher $R_{P}$ means that there was less loss in potential sugar (cellulose) during pretreatment.
Enzymatic hydrolysis efficiency $\left(E_{H}\right)$ is expressed in terms of the percentage of cellulose converted to glucose by enzymatic hydrolysis and calculated using the following equation:

$$
E_{H}(\%)=\frac{c \times V}{1.11 \times W_{H} \times C_{\mathrm{AP}}} \times 100 \%,
$$

where $c(\mathrm{~g} / \mathrm{L})$ is the concentration of glucose in the flask slurry after $48 \mathrm{~h}$ hydrolysis, $V(\mathrm{~L})$ is the total volume of the slurry, $W_{H}(\mathrm{~g})$ is the dry weight of the biomass loaded into the flask, and $C_{\mathrm{AP}}(\%)$ is the cellulose content in the biomass before hydrolysis (after pretreatment). The factor 1.11 is the celluloseto-glucose conversion factor, which reflects the weight gain in converting cellulose to glucose in hydrolysis.

Total cellulose conversion rate $\left(R_{T}\right)$ is used to evaluate the overall efficiency of pretreatment and enzymatic hydrolysis in converting cellulose to glucose. It is the percentage of cellulose in unpretreated biomass that is converted to glucose after enzymatic hydrolysis. It is the product of enzymatic hydrolysis efficiency $\left(E_{H}\right)$ and cellulose recovery rate after pretreatment $\left(R_{P}\right)$ :

$$
R_{T}(\%)=\frac{E_{H} \times R_{P}}{100 \%} .
$$

In this study, total sugar yield $\left(Y_{T}\right)$ provides a straightforward interpretation about how much glucose a unit dry weight of biomass (before pretreatment) can yield through biochemical conversion. Its calculation is described as follows:

$$
Y_{T}\left(\frac{\text { g glucose }}{\text { g biomass }}\right)=\frac{c \times V \times W_{\mathrm{AP}}}{W_{H} \times W_{\mathrm{BP}}} .
$$

3.4. Statistical Analysis. Chemical compositions in Tables 1 and 3 are reported as the means with standard deviations in brackets. Multiple comparisons using one-way analysis of variance (ANOVA) were conducted using Minitab software (Version 16, Minitab Inc., State College, PA, USA) to check the existence of significant differences within the means. Error bars in figures are drawn using standard deviations. Different letters ( $a, b, c$, and d) indicate that the means are significantly different in the order of $a>b>c>d$ based on Fisher LSD test at level of $\alpha=0.05$. The same letters indicate that means have statistically no difference.

\section{Results and Discussion}

4.1. Effects of Screen Size on Energy Consumption in Biomass Size Reduction. Figure 8 shows that screen size had a significant effect on energy consumption in size reduction of big bluestem. Energy consumption decreased greatly as screen size increased. Energy consumption was as high as 0.13 and $0.12 \mathrm{Wh} / \mathrm{g}$ for screen sizes of 1 and $2 \mathrm{~mm}$, respectively. When using 4 and $8 \mathrm{~mm}$ screens, energy consumption decreased to 0.09 and $0.08 \mathrm{Wh} / \mathrm{g}$, respectively. It was observed that a major factor that caused the high energy consumption when using a smaller screen size was that it took longer time to produce the same weight of particles than using larger screen sizes. 
TABLE 2: Energy consumption in biomass size reduction using Retsch SM2000 knife mill.

\begin{tabular}{|c|c|c|c|c|}
\hline Biomass material & Moisture content (\% dry weight basis) & Screen size $(\mathrm{mm})$ & Energy consumption (Wh/g) & Reference \\
\hline \multirow{4}{*}{ Big bluestem (whole stems) } & \multirow{4}{*}{5} & 1 & 0.13 & \multirow{4}{*}{ This study } \\
\hline & & 2 & 0.12 & \\
\hline & & 4 & 0.09 & \\
\hline & & 8 & 0.07 & \\
\hline \multirow{4}{*}{ Miscanthus (segments) } & \multirow{4}{*}{$7-10$} & 1 & 0.28 & \multirow{4}{*}[20,21]{} \\
\hline & & 2 & 0.10 & \\
\hline & & 4 & 0.06 & \\
\hline & & 8 & 0.04 & \\
\hline \multirow{4}{*}{ Switchgrass (segments) } & \multirow{4}{*}{$7-10$} & 1 & 0.27 & \multirow{4}{*}[20,21]{} \\
\hline & & 2 & 0.12 & \\
\hline & & 4 & 0.06 & \\
\hline & & 8 & 0.03 & \\
\hline \multirow{3}{*}{ Wheat straw (whole stems) } & \multirow{3}{*}{12} & 1 & 0.16 & \multirow{3}{*}[26]{} \\
\hline & & 2 & 0.12 & \\
\hline & & 8 & 0.06 & \\
\hline \multirow{2}{*}{ Sorghum stalk (whole stems) } & \multirow{2}{*}{9} & 1.5 & 0.09 & \multirow{2}{*}[27]{} \\
\hline & & 8 & 0.04 & \\
\hline Kochia (whole stems) & 10 & 1.5 & 0.07 & {$[27]$} \\
\hline
\end{tabular}

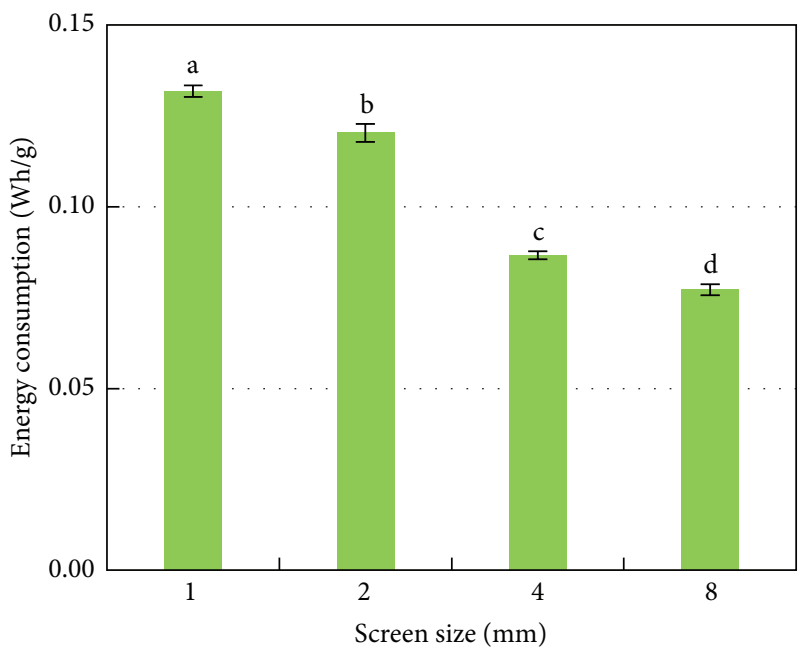

FIGURE 8: Effects of screen size on energy consumption in size reduction of big bluestem.

TABle 3: Chemical compositions (\% dry weight basis) of big bluestem after pretreatment.

\begin{tabular}{lcccc}
\hline \multirow{2}{*}{ Component } & \multicolumn{4}{c}{ Screen size $(\mathrm{mm})$} \\
& 1 & 2 & 4 & 8 \\
\hline Cellulose & $56.4(1.2)^{\mathrm{a}}$ & $58.6(0.9)^{\mathrm{a}}$ & $58.4(0.5)^{\mathrm{a}}$ & $58.9(0.6)^{\mathrm{a}}$ \\
Hemicellulose & $5.7(0.6)^{\mathrm{b}}$ & $5.2(0.3)^{\mathrm{b}}$ & $4.9(0.7)^{\mathrm{b}}$ & $4.6(0.2)^{\mathrm{b}}$ \\
Lignin & $28.6(0.7)^{\mathrm{c}}$ & $28.0(1.3)^{\mathrm{c}}$ & $29.8(0.2)^{\mathrm{c}}$ & $29.6(1.0)^{\mathrm{c}}$ \\
\hline
\end{tabular}

The same letters indicate that means have statistically no difference based on Fisher LSD test at level of $\alpha=0.05$.

In the literature, there are no reports on energy consumption in size reduction of big bluestem. There are some reports on energy consumption about size reduction of other types of herbaceous biomass using the Retsch SM 2000 knife mill. Energy consumption data when using different screen sizes on the knife mill were summarized in Table 2. As indicated in the table, using smaller screen size would consume more energy to produce the same amount of biomass particles. It was noticed that, in previous studies reported by Miao et al. $[19,20]$, herbaceous biomass loaded into the knife mill was biomass segments prepared by a chopping machine before knife milling, whereas other studies in Table 2 used whole stem of herbaceous biomass as input materials to the knife mill.

4.2. Effects of Screen Size on Cellulose Recovery Rate after Pretreatment. Table 3 lists big bluestem chemical composition after pretreatment. It was noticed that chemical compositions of particles produced with different screen sizes are approximately the same.

Figure 9 shows that there was more biomass weight loss in pretreatment for particles produced with a smaller screen size. The major weight loss in pretreatment was caused by the decomposition of hemicellulose. The primary objective of dilute sulfuric acid pretreatment is to break down the shield formed by highly associated lignin and hemicellulose by decomposing hemicellulose to acid-soluble products (i.e., xylose), so that cellulose can be released and become more accessible to enzymes in enzymatic hydrolysis [33]. However, a side effect is that a small amount of cellulose may be degraded to hydroxymethyl-furfural (HMF) [33]. HMF is soluble in the pretreatment liquid and will be separated from the solid biomass after pretreatment. Only the solid biomass collected after pretreatment goes into enzymatic hydrolysis. The degradation of cellulose to HMF results in potential sugar (cellulose) loss and leads to decreasing total sugar yield [27]. 


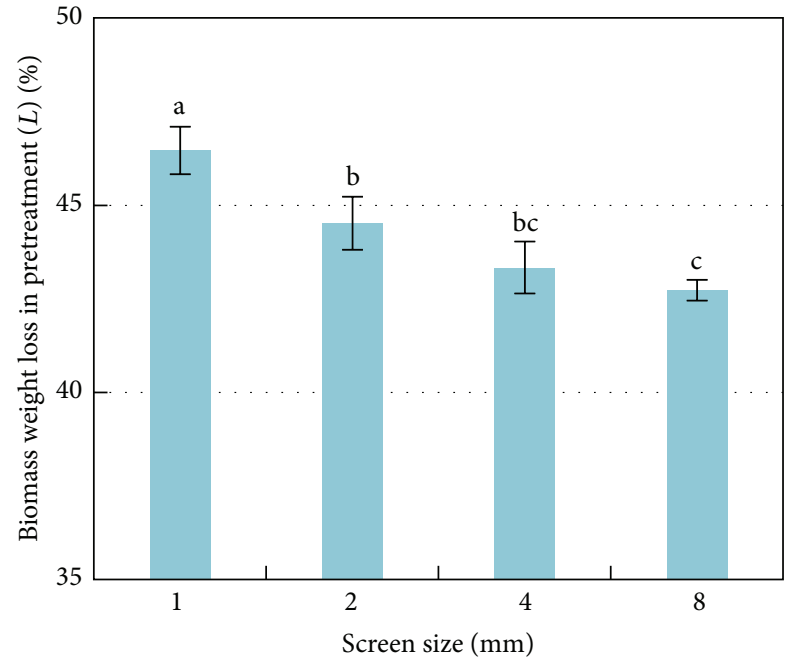

FIGURE 9: Effects of screen size on biomass weight loss in pretreatment.

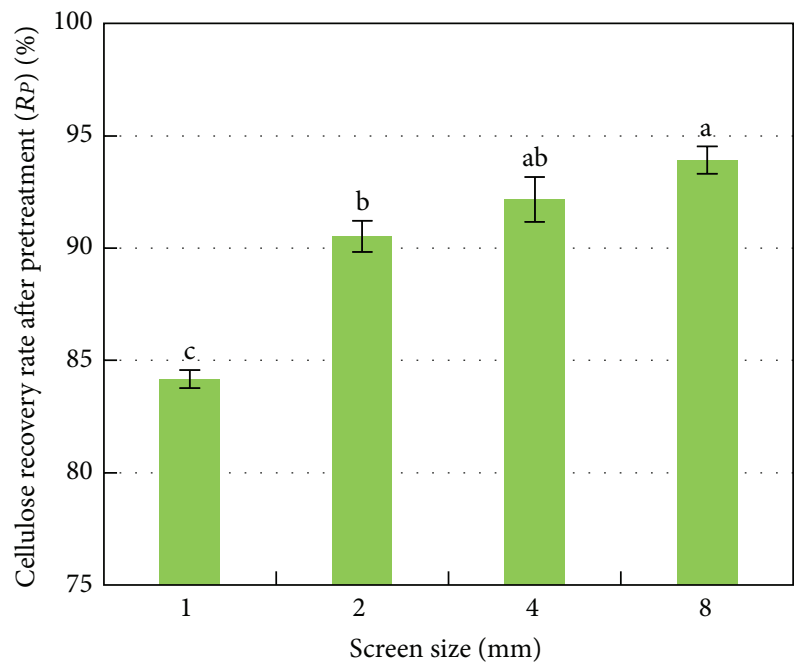

Figure 10: Effects of screen size on cellulose recovery rate after pretreatment.

Figure 10 shows that cellulose recovery rate after pretreatment was higher for big bluestem particles produced with a larger screen size. It is believed that biomass with a smaller particle size will be more amenable to pretreatment; as a result, higher cellulose degradation and hemicellulose decomposition will happen for smaller particles comparing to larger ones under the same severe pretreatment. Ballesteros et al. [34] reported the same trend from a similar study. They used softwood chips of three size levels $(2-5,5-8$, and $8-12 \mathrm{~mm}$ ) treated with steam-explosion pretreatment. They observed that chip size had a significant influence on cellulose recovery rate after pretreatment. As chip size increased, cellulose recovery rate after pretreatment increased.

As lignin has a complex three-dimensional aromatic structure and heterogeneity, its structural properties might be altered differently by experiencing different degree of

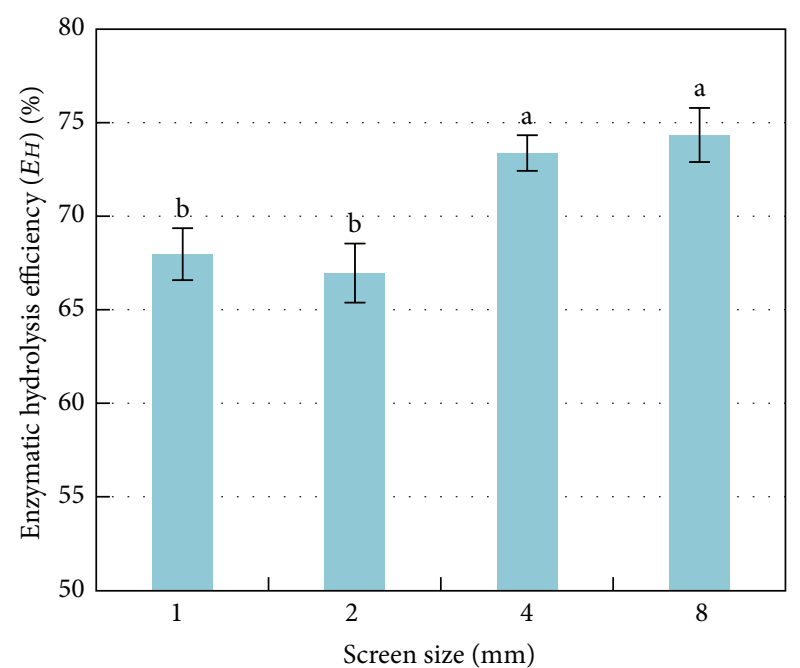

FIGURE 11: Effects of screen size on enzymatic hydrolysis efficiency.

mechanical comminution when using three screen sizes in size reduction and later by dilute acid pretreatment. As a future research question, these structural property changes can be further investigated by conducting FTIR spectroscopy of lignin processed with different screen sizes before and after pretreatment [35].

4.3. Effects of Screen Size on Enzymatic Hydrolysis Efficiency. As shown in Figure 11, big bluestem particles produced with 4 or $8 \mathrm{~mm}$ screen sizes had higher enzymatic hydrolysis efficiency than the particles produced with 1 or $2 \mathrm{~mm}$ screen sizes. The difference in enzymatic hydrolysis efficiency between particles produced with 4 and $8 \mathrm{~mm}$ or between those produced with 1 and $2 \mathrm{~mm}$ screen sizes was insignificant. One possible explanation given by Sarkar et al. [16] is that fine biomass particles may impose negative effects on the subsequent processing. They may cause the generation of clumps during enzymatic hydrolysis. Theerarattananoon et al. [30] reported similar results. Three types of biomass materials (big bluestem, corn stover, and wheat straw) were size reduced on a hammer mill with screen sizes of 3.2 and $6.5 \mathrm{~mm}$. Particles produced with screen size of $6.5 \mathrm{~mm}$ had higher enzymatic hydrolysis efficiency than those produced with screen size of $3.2 \mathrm{~mm}$. In their experiments, there was a pelleting process (the agglomeration of small particles into firm, uniformly shaped granules by the means of mechanical processes) between size reduction and pretreatment.

4.4. Effects of Screen Size on Total Cellulose Conversion Rate and Total Sugar Yield. As shown in Figure 12, big bluestem particles produced with larger screen sizes achieved higher total cellulose conversion rate. Nearly $70 \%$ of the cellulose in particles produced with the $8 \mathrm{~mm}$ screen size was converted to glucose, which was about $20 \%$ higher than that produced with the $1 \mathrm{~mm}$ screen size. 


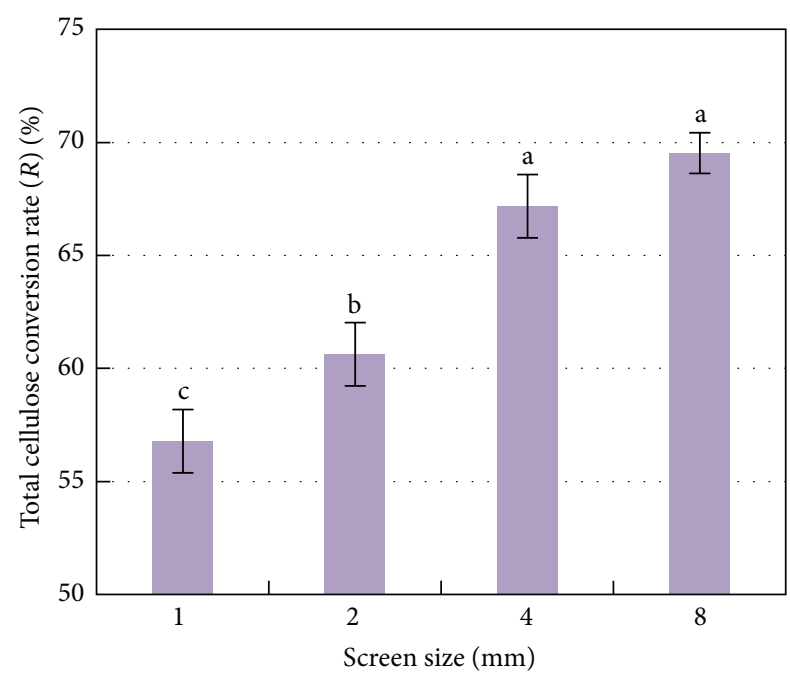

FIGURE 12: Effects of screen size on total cellulose conversion rate.

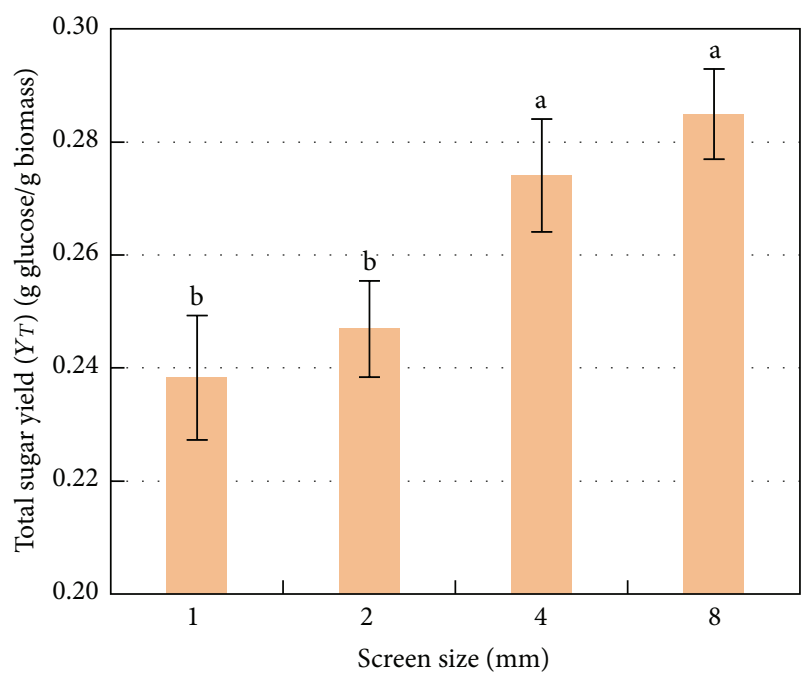

FIGURE 13: Effects of screen size on total sugar yield.

Figure 13 shows total sugar yield results. As screen size used in size reduction increased, total sugar yield of the produced particles increased. Big bluestem particles produced with $8 \mathrm{~mm}$ screen size yielded $20 \%$ more sugar than those produced with $1 \mathrm{~mm}$ screen size.

\section{Conclusions}

This study presents the first effort in investigating the effects of screen size used in biomass size reduction throughout the biochemical conversion of big bluestem to fermentable sugar. Major conclusions are as follows:

(1) Energy consumption in biomass size reduction increased greatly as screen size became smaller (from 8 to $1 \mathrm{~mm})$.
(2) Big bluestem particles produced with a larger screen size had higher cellulose recovery rate after pretreatment.

(3) Big bluestem particles produced with larger screen sizes ( 4 and $8 \mathrm{~mm}$ ) had higher enzymatic hydrolysis efficiency, higher total cellulose conversion rate, and higher total sugar yield than those produced with smaller screen sizes ( 1 and $2 \mathrm{~mm}$ ).

\section{Conflict of Interests}

The authors declare that there is no conflict of interests regarding the publication of this paper.

\section{Acknowledgments}

This study is supported by the U.S. National Science Foundation through Award 0970112. Publication of this paper was funded in part by the Kansas State University Open Access Publishing Fund.

\section{References}

[1] J. Fargione, J. Hill, D. Tilman, S. Polasky, and P. Hawthorne, "Land clearing and the biofuel carbon debt," Science, vol. 319, no. 5867, pp. 1235-1238, 2008.

[2] Energy Information Administration, "Annual energy review 2011,” Report No. DOE/EIA-0384, 2011, http://www.eia.gov/ totalenergy/data/annual/pdf/aer.pdf.

[3] U.S. Department of Energy, "Biomass as feedstocks for a bioenergy and byproducts industry: the technical feasibility of a billion-ton annual supply," http://feedstockreview.ornl.gov/ pdf/billion_ton_vision.pdf.

[4] U.S. Department of Energy, "U.S. billion-ton update: biomass supply for a bioenergy and bioproducts industry," http://wwwl .eere.energy.gov/biomass/pdfs/billion_ton_update.pdf.

[5] P. Moriarty and D. Honnery, "Low-mobility: the future of transport," Futures, vol. 40, no. 10, pp. 865-872, 2008.

[6] E. M. Rubin, "Genomics of cellulosic biofuels," Nature, vol. 454, no. 7206, pp. 841-845, 2008.

[7] J. Gan, W. Yuan, L. Johnson, D. Wang, R. Nelson, and K. Zhang, "Hydrothermal conversion of big bluestem for biooil production: the effect of ecotype and planting location," Bioresource Technology, vol. 116, pp. 413-420, 2012.

[8] F. Gould and R. Shaw, Grass Systematics, Texas A\&M University Press, College Station, Tex, USA, 2nd edition, 1963.

[9] A. K. Knapp, J. M. Briggs, D. C. Hartnett, and S. L. Collins, Grassland Dynamics: Long-Term Ecological Research in Tallgrass Prairie, Oxford University Press, New York, NY, USA, 1998.

[10] L. Wei, L. O. Pordesimo, C. Igathinathane, and W. D. Batchelor, "Process engineering evaluation of ethanol production from wood through bioprocessing and chemical catalysis," Biomass and Bioenergy, vol. 33, no. 2, pp. 255-266, 2009.

[11] P. Kumar, D. M. Barrett, M. J. Delwiche, and P. Stroeve, "Methods of pretreatment of lignocellulosic biomass for efficient hydrolysis and biofuel production," Industrial \& Engineering Chemistry Research, vol. 48, pp. 3713-3729, 2009.

[12] S. Paulrud, J. E. Mattsson, and C. Nilsson, "Particle and handling characteristics of wood fuel powder: effects of different mills," Fuel Processing Technology, vol. 76, no. 1, pp. 23-39, 2002. 
[13] M. T. Holtzapple, A. E. Humphrey, and J. D. Taylor, "Energy requirements for the size reduction of poplar and aspen wood," Biotechnology and Bioengineering, vol. 33, no. 2, pp. 207-210, 1989.

[14] L. Cadoche and G. D. López, "Assessment of size reduction as a preliminary step in the production of ethanol from lignocellulosic wastes," Biological Wastes, vol. 30, no. 2, pp. 153$157,1989$.

[15] V. S. P. Bitra, A. R. Womac, N. Chevanan et al., "Direct mechanical energy measures of hammer mill comminution of switchgrass, wheat straw, and corn stover and analysis of their particle size distributions," Powder Technology, vol. 193, no. 1, pp. 32-45, 2009.

[16] N. Sarkar, S. K. Ghosh, S. Bannerjee, and K. Aikat, "Bioethanol production from agricultural wastes: an overview," Renewable Energy, vol. 37, no. 1, pp. 19-27, 2012.

[17] L. Tabil, P. Adapa, and M. Kashaninejad, "Biomass feedstock pre-processing-part 1: pre-treatment," in Biofuel's Engineering Process Technology, M. A. S. Bernardes, Ed., pp. 411-438, InTech, Rijeka, Croatia, 2011.

[18] N. Mosier, C. Wyman, B. Dale et al., "Features of promising technologies for pretreatment of lignocellulosic biomass," Bioresource Technology, vol. 96, no. 6, pp. 673-686, 2005.

[19] A. Pandey, C. Larroche, S. C. Ricke, C. Dussap, and E. Gnansounou, Biofuels: Alternative Feedstocks and Conversion Processes, Academic Press, San Diego, Calif, USA, 2011.

[20] Z. Miao, T. E. Grift, A. C. Hansen, and K. C. Ting, "Specific energy consumption of biomass particle production and particle physical property," in Proceedings of the American Society of Agricultural and Biological Engineers Annual International Meeting (ASABE' 10), pp. 584-604, Pittsburgh, Pa, USA, June 2010.

[21] Z. Miao, T. E. Grift, A. C. Hansen, and K. C. Ting, "Energy requirement for comminution of biomass in relation to particle physical properties," Industrial Crops and Products, vol. 33, no. 2, pp. 504-513, 2011.

[22] B. C. Vidal Jr., B. S. Dien, K. C. Ting, and V. Singh, "Influence of feedstock particle size on lignocellulose conversion-a review," Applied Biochemistry and Biotechnology, vol. 164, no. 8, pp. 1405-1421, 2011.

[23] S. G. Allen, D. Schulman, J. Lichwa, M. J. Antal Jr., E. Jennings, and R. Elander, "A comparison of aqueous and dilute-acid single-temperature pretreatment of yellow poplar sawdust," Industrial and Engineering Chemistry Research, vol. 40, no. 10, pp. 2352-2361, 2001.

[24] Q. A. Nguyen, M. P. Tucker, F. A. Keller, and F. P. Eddy, "Two-stage dilute-acid pretreatment of softwoods," Applied Biochemistry and Biotechnology, vol. 84-86, pp. 561-576, 2000.

[25] C. Karunanithy and K. Muthukumarappan, "Optimization of alkali, big bluestem particle size, and extruder parameters for maximum enzymatic sugar recovery using response surface methodology," BioResources, vol. 6, no. 1, pp. 762-790, 2011.

[26] T. W. Deines and Z. J. Pei, "Power consumption study in knife milling of wheat straw," Transactions of the North American Manufacturing Research Institute of SME, vol. 38, pp. 38-191, 2010.

[27] T. W. Deines, D. Nottingham, and Z. J. Pei, "Effects of biomass type and sieve size on power consumption in knife milling," in Proceedings of the IIE Annual Conference and Expo, Cancun, Mexico, June 2010.

[28] A. Sluiter, B. Hames, D. Hyman et al., "Determination of total solids in biomass and total dissolved solids in liquid process samples," Tech. Rep. NREL/TP-510-42621, National Renewable Energy Laboratory, 2008, http://www.nrel .gov/biomass/pdfs/42621.pdf.

[29] K. Zhang, L. Johnson, R. Nelson, W. Yuan, Z. Pei, and D. Wang, "Chemical and elemental composition of big bluestem as affected by ecotype and planting location along the precipitation gradient of the Great Plains," Industrial Crops and Products, vol. 40, no. 1, pp. 210-218, 2012.

[30] K. Theerarattananoon, F. Xu, J. Wilson et al., "Effects of the pelleting conditions on chemical composition and sugar yield of corn stover, big bluestem, wheat straw, and sorghum stalk pellets," Bioprocess and Biosystems Engineering, vol. 35, no. 4, pp. 615-623, 2012.

[31] R. Kumar, S. Singh, and O. V. Singh, "Bioconversion of lignocellulosic biomass: biochemical and molecular perspectives," Journal of Industrial Microbiology \& Biotechnology, vol. 35, no. 5, pp. 377-391, 2008.

[32] A. Sluiter, B. Hames, R. Ruiz et al., "Determination of structural carbohydrates and lignin in biomass," Tech. Rep. NREL/TP-51042618, 2011, http://www.nrel.gov/biomass/pdfs/42618.pdf.

[33] G. Hu, J. A. Heitmann, and O. J. Rojas, "Feedstock pretreatment strategies for producing ethanol from wood, bark, and forest residues," BioResources, vol. 3, no. 1, pp. 270-294, 2008.

[34] I. Ballesteros, J. M. Oliva, A. A. Navarro, A. González, J. Carrasco, and M. Ballesteros, "Effect of chip size on steam explosion pretreatment of softwood," Applied Biochemistry and Biotechnology_Part A: Enzyme Engineering and Biotechnology, vol. 84-86, pp. 97-110, 2000.

[35] H. Li and A. G. McDonald, "Fraction and characterization of industrial lignins," Industrial Crops and Products, vol. 62, pp. 6776, 2014. 

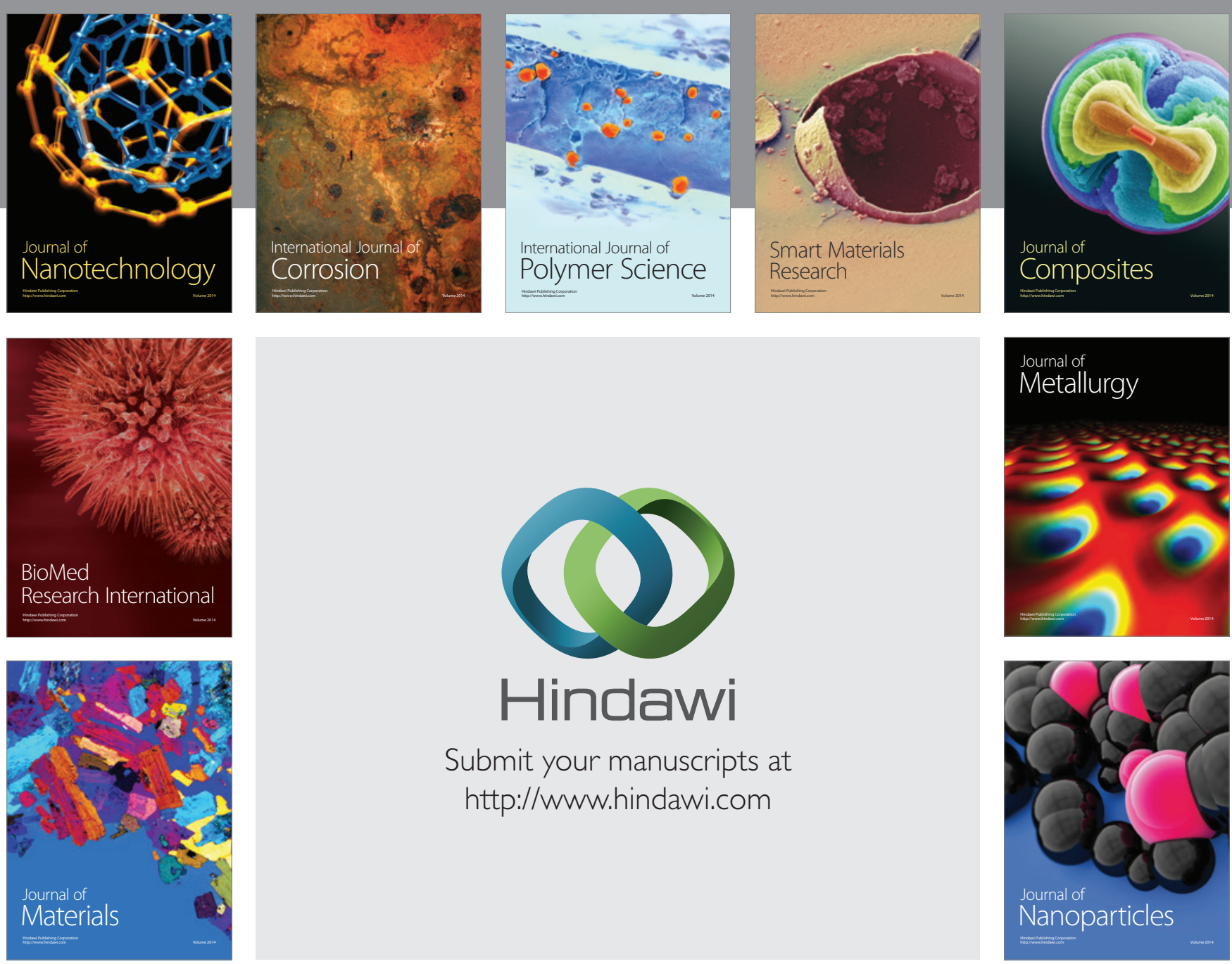

Submit your manuscripts at http://www.hindawi.com
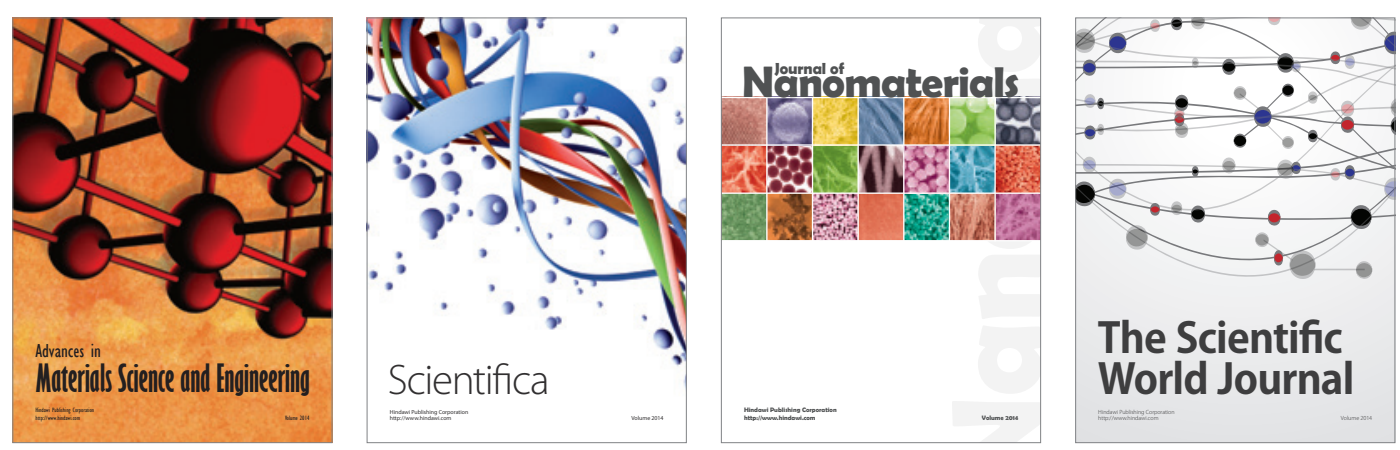

\section{The Scientific World Journal}
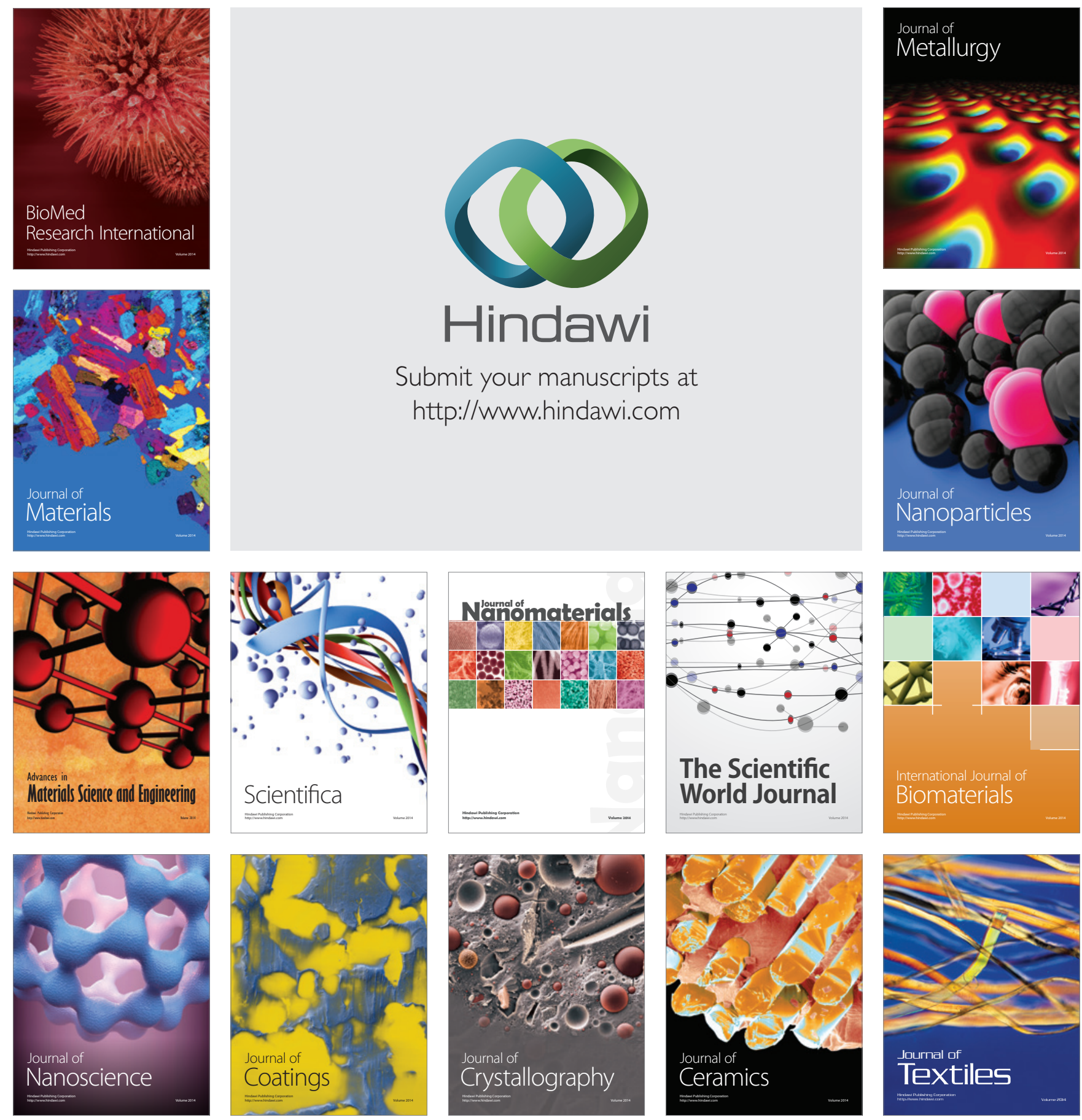